\title{
Micro-computed Tomography of Teeth as an Alternative Way to Detect and Analyse Vitamin D Deficiency.
}

\section{Authors' names:}

COLOMBO Antony ${ }^{\mathrm{a}, \mathrm{b}, \mathrm{c}^{*}, \mathrm{D}^{\prime} \text { ORTENZIO Lori }}{ }^{\mathrm{d}}$, BERTRAND Benoit ${ }^{\mathrm{e}}$, COQUEUGNIOT Hélène $^{\mathrm{a}, \mathrm{b}, \mathrm{c}}$, KNÜSEL Christopher J. ${ }^{\mathrm{b}}$, KAHLON Bonnie ${ }^{\mathrm{d}}$, BRICKLEY Megan ${ }^{\mathrm{d}}$.

Authors' affiliations:

a- Ecole Pratique des Hautes Etudes, PSL University Paris, Chaire d'anthropologie biologique Paul Broca.

b- UMR 5199 PACEA, University of Bordeaux, CNRS, MCC; LabEx Sciences archéologiques de Bordeaux, ${ }^{\circ}$ ANR-10-LABX-52, Bâtiment B8, Allée Geoffroy Saint- Hilaire, CS50023, F-33615 Pessac, France.

c- Max Planck Institute for Evolutionary Anthropology, Department of Human Evolution, Deutscher Platz 6, D-04103 Leipzig, Germany.

d- Department of Anthropology, McMaster University, 1280 Main Street West, Hamilton, Ontario L8S 4L9, Canada

e- Forensic Taphonomy Unit, EA 7367, Lille University, France

Keywords: Vitamin D, dental microstructure, interglobular dentine, non-destructive

*corresponding authors: Dr. Antony Colombo, address: École Pratique des Hautes Études, UMR 5199 PACEA, University of Bordeaux, Bâtiment B8, Allée Geoffroy Saint-Hilaire, CS 50023, 33615 Pessac cedex, FRANCE, e-mail address: colomboantony@gmail.com.

\begin{abstract}
(200 words):
This contribution presents the first application of micro-computed tomography $(\mu \mathrm{CT})$ to study pathological mineral defects associated with the vitamin D deficiency, namely interglobular dentine (IGD), within the mineral matrix of archaeological teeth from three French medieval cases. To date, such an approach has only been used once in a clinical setting. Through this work, we evaluate potential benefits of this alternative approach and the contribution such work could make to anthropological debates, through analysis of rare teeth of human or non-human fossils or teeth of individuals where more destructive techniques cannot be applied.
\end{abstract}




\section{The importance of Vitamin D deficiency detection in the past populations}

Vitamin D plays a fundamental role in the metabolism of calcium and phosphorus in the body, thus its optimal serum level is critical for good bone and dental health (Foster et al., 2014, Wang, 2009). Its concentration in an organism is dependent on synthesis in the skin upon exposure to the ultraviolet radiation (UV-B) of sunlight (Jablonski and Chaplin, In press) and to a lesser extent nutritional intake. Prior to the development of fortified foods, lack of skin exposure to UVB would have been the main reason for deficiency (Jones, In press). Both environmental and social conditions play a role in achieving optimal health (Brickley et al., 2014).

A severe vitamin D deficiency can lead to rickets and osteomalacia, both characterised by poor mineralisation of bone resulting in bone deformities. Traditionally, in palaeopathology, macroscopic analysis of bone lesions in an active or healed state has been the only way to identify vitamin D deficiency (Mays et al., 2006) and various limitations have been highlighted (Brickley et al., 2010, Brickley et al., In press). Recently, D'Ortenzio et al. (2016) demonstrated in archaeological populations the presence of a microscopic histological sign in the teeth of individuals suffering from even slight vitamin D deficiency: interglobular dentine (IGD), a dentine mineralization defect. In cases where skeletal evidence of previous episodes of rickets may be missed, the histological examination of tooth thin sections to detect IGD can provide information on the number, timing, and severity of episodes of deficiency (D'Ortenzio et al., 2016).

Today, despite increased understanding and availability of supplements and fortified foods, vitamin D deficiency is still a major public health problem and affects approximately $15 \%$ of the population worldwide (Huh and Gordon, 2008). Thus, we might also expect cases of rickets to be present in many past communities (see Brickley et al., 2017). Vitamin D synthesis is at the centre of the debate about the evolution of skin colour (Jablonski and Chaplin, In press) and variations exist in its synthesis among primates (Ziegler et al., 2015). It is thus a useful means to identify vitamin D deficiency in both non-human primates and all members of the human lineage.

For a wide range of reasons, but especially curatorial ones, there are many teeth in the world for which no permission to section or sample will ever be given. The rarity of human fossils is the reason why destructive work is very uncommon. Also, collections of identified skeletons, such as the Robert J. Terry anatomical collection (Hunt and Albanese, 2005) in the USA (Smithsonian Institution's National Museum of Natural History, Washington D.C.) or similar collections in Europe such as the Luís Lopes collection (Cardoso, 2006) in Portugal (Bocage Museum, Lisbon) have important scientific value because much information about the deceased is known (e.g. age at death, sex, pathological conditions, profession). The development of new methods of individual identification (e.g. estimation of age and sex) is based on these types of collections and, as the teeth are very useful for age estimation, there is a ban on destructive work.

The histological detection of IGD involves production of thin sections that permanently damage the tooth. In contrast, micro-computed tomography $(\mu \mathrm{CT})$ is a useful X-ray technique for archaeological human remains because it does not damage the material investigated 
(Coqueugniot et al., 2015), nor does it affect the preservation of ancient DNA (aDNA) (Immel et al., 2016). Moreover, this investigative method has been popularized over the last decade and has become quite common in archaeological science research on teeth, for example in the quantification of dental size and tooth morphology (Benazzi et al., 2011), or characterization of tooth microstructure (Tafforeau and Smith, 2008).

To our knowledge, only one clinical study has used $\mu \mathrm{CT}$ analysis for the identification of IGD in modern teeth (Ribeiro et al., 2015), and to date this methodology has not been applied to archaeological remains. This paper will focus on the evaluation of how $\mu \mathrm{CT}$ analyses of teeth can contribute to detecting IGD in three archaeological examples and assess the advantages and limitations of the use of $\mu \mathrm{CT}$.

\section{Material and Methods}

Four teeth from three archaeological individuals were analysed for this research (see Table 1). We first selected a permanent lower right first incisor $\left(\mathrm{RI}_{1}\right)$ and a lower right canine $\left(\mathrm{RC}_{1}\right)$ of individual SJ892, who presents both bone and dental signs of severe vitamin D deficiency (Figure 1a, b) and comes from the medieval cemetery (A.D. 1225-1798) associated with the church of Saint-Jacques in Douai, France (Table 1). The second and third cases come from the cemetery of Saint-Étienne de Toulouse, France (11th-13th centuries A.D.). We selected the permanent lower left first molar $\left(\mathrm{LM}_{1}\right)$ of individual STE15, which only shows dental changes potentially related to vitamin D deficiency (Figure 1b, Table 1), and the permanent upper left first molar $\left(\mathrm{LM}^{1}\right)$ of individual STE311 showing neither radiological nor macroscopic signs of rickets (Figure 1b, Table 1).

[Figure 1, here, 1.5 columns]

All the four selected teeth were analysed. The same tooth was analysed with $\mu \mathrm{CT}$ and histology for individuals STE15 and STE311. For SJ892, RI $I_{1}$ was $\mu$ CT-scanned and $\mathrm{RC}_{1}$ was used for histology. The $\mathrm{RC}_{1}$ for individual $\mathrm{SJ} 892$ had been sectioned for a previous study and found to contain clear evidence of grade 3 IGD (D'Ortenzio et al., 2016). Because vitamin D deficiency is a systemic condition all developing teeth will be affected, so we selected a tooth $\left(\mathrm{RI}_{1}\right)$ for $\mu \mathrm{CT}$ analysis that forms at approximately the same time (Hillson, 1996).

The teeth $\mathrm{RI}_{1}$ of SJ892, $\mathrm{LM}_{1}$ of STE15 and $\mathrm{LM}^{1}$ of STE311 were $\mu \mathrm{CT}$-scanned with a GE v|tome $\mid \mathrm{x} S$ at a resolution of $11 \mu \mathrm{m}$ (acquisition parameters: $140 \mathrm{kV}, 110 \mu \mathrm{A}, 2550$ projections, $360^{\circ}, 500 \mathrm{~ms}$, frame averaging of $3,0.1 \mathrm{~mm}$ copper filter). Then, $\mu \mathrm{CT}$ images of the teeth were analysed with Avizo 8.0 software to identify the presence or absence, and, if relevant, the number IGD episodes.

Table 1: Characteristics of individuals and teeth selected for comparison between $\mu \mathrm{CT}$ and histological analyses in the detection of interglobular dentine (F: Female, U: Unknown sex, L: left, R: right). Bone or dental signs associated with rickets are diagnosed following respectively Brickley et al. (2010) and D'Ortenzio et al. (In press) 


\begin{tabular}{|c|c|c|c|c|c|c|}
\hline \multirow{2}{*}{$\begin{array}{l}\text { Archaeological } \\
\text { Context }\end{array}$} & \multirow[t]{2}{*}{ Individual } & \multirow[t]{2}{*}{ Sex } & \multirow{2}{*}{$\begin{array}{l}\text { Age-at- } \\
\text { death } \\
\text { (years) }\end{array}$} & \multicolumn{2}{|c|}{ Potential signs of rickets } & \multirow{2}{*}{$\begin{array}{l}\text { Tooth } \\
\text { selected }\end{array}$} \\
\hline & & & & Bone $^{a}$ & Dental $^{b}$ & \\
\hline $\begin{array}{l}\text { Saint Jacques church, } \\
\text { Douai (France) } \\
\text { A.D. } 1225-1798\end{array}$ & SJ892 & $\mathrm{F}$ & $20+$ & $\begin{array}{l}\text { Sequelae of } \\
\text { rickets: bowing of } \\
\text { both left and right } \\
\text { tibiae and fibulae }\end{array}$ & $\begin{array}{l}\text { Pulp chamber } \\
\text { morphology } \\
\text { changes of the } \\
\text { left } \mathrm{M}_{1}\end{array}$ & $\begin{array}{l}\mathrm{RI}_{1} \\
\mathrm{RC}_{1}\end{array}$ \\
\hline $\begin{array}{l}\text { Saint-Étienne de } \\
\text { Toulouse (Toulouse, } \\
\text { France) }\end{array}$ & STE15 & $\mathrm{U}$ & $19-21$ & None & $\begin{array}{l}\text { Pulp chamber } \\
\text { morphology } \\
\text { changes }\end{array}$ & $\mathrm{LM}_{1}$ \\
\hline $\begin{array}{l}\text { Funerary occupation: } \\
11^{\text {th }}-13^{\text {th }} \text { centuries A.D. } \\
\text { (De Filippo R. et al., } \\
\text { 1986, De Filippo R. et } \\
\text { al., 1988) }\end{array}$ & STE311 & $\mathrm{U}$ & $4-6$ & None & None & $\mathrm{LM}^{1}$ \\
\hline
\end{tabular}

After, the $\mu \mathrm{CT}$ phase, $\mathrm{RC}_{1}$ of SJ892, $\mathrm{LM}_{1}$ of STE15 and $\mathrm{LM}^{1}$ of STE311 were prepared for histological analysis. They were sectioned through the mesio-distal plane with a precision sectioning saw (Buehler IsoMet 1000) and thin sections of $100 \mu \mathrm{m}$ thickness were lapped, polished and mounted on a glass microscope slide with UV activated adhesive. Thin sections were examined for IGD presence or absence using an Olympus BX51 digital microscope. IGD in thin sections was scored following the severity scale set out in D'Ortenzio et al. (2016) from Grade 0 (absence of IGD) to Grade 3 (>75\% of the area observed are IGD). In addition, because IGD follows the incremental growth of dentine, we estimated the age when the deficiency event(s) occurred based on the tooth developmental charts of Moorrees et al. (1963).

\section{Results}

SJ892 had clear skeletal indicators of rickets, and IGD was observed in both $\mu \mathrm{CT}$ and histological thin-sections (Table 2). However, $\mu \mathrm{CT}$ images showed two separate lines of IGD in the coronal dentine (Figure 2a-b), whereas the histological image showed a single band of IGD. Closer examination following evaluation of $\mu \mathrm{CT}$ data revealed two distinct lines of grade 3 IGD (top and bottom of the IGD band) with less severe IGD in the mid-section of the band, suggesting it was likely part of the same episode occurring between 1 and 2 years of age (Figure 2c). The difference in the number of IGD lines observed could be due to the individual experiencing long-standing deficiency that included a period when the deficiency was less severe (such as seasonal variation), but only the more severe period of deficiency appeared on $\mu \mathrm{CT}$ (observed as two separate bands of IGD), suggesting that $\mu \mathrm{CT}$ may not always pick up less severe cases of IGD.

[Figure 2, here, 2 columns]

STE15 did not display skeletal indicators of rickets, but the $\mathrm{M}_{1}$ was selected for analysis as evaluation of X-rays of the $\mathrm{LM}_{1}$ revealed a 'chair-shaped' pulp chamber in the $\mathrm{M}_{1}$ that could be linked to deficiency during pulp chamber initiation (D'Ortenzio et al., In press) (See Table 2). Histological examination of the tooth showed very slight IGD histologically (< grade 1) (See Figure 3d), which may have formed in naturally occurring spaces in the dentine matrix that 
occurred while the tooth was developing (D'Ortenzio et al., 2018). Deficiency that is less than grade 1 is not severe enough to cause pulp chamber changes (D'Ortenzio et al., In press) confirming that the absence of $\mu \mathrm{CT}$ identification of IGD is due to absence of a deficiency event. Morphological changes of the pulp chamber in the $\mathrm{M}_{1}$ are likely due to reparative secondary dentine deposition caused by severe dental wear of the enamel (see D'Ortenzio et al., 2016: Supplementary Data).

Table 2 - Results of interglobular dentine detection with $\mu \mathrm{CT}$ and histological analyses (DIGD: developmental IGD).

\begin{tabular}{|c|c|c|c|c|c|c|}
\hline \multirow{2}{*}{ Individual } & \multicolumn{2}{|c|}{ IGD detection } & \multicolumn{2}{|c|}{$\begin{array}{c}\text { Number/approximate } \\
\text { period of time of IGD events }\end{array}$} & \multirow{2}{*}{$\begin{array}{c}\text { Age at } \\
\text { deficiency } \\
\text { (years) }\end{array}$} & \multirow{2}{*}{$\begin{array}{l}\text { Histological } \\
\text { grade }\end{array}$} \\
\hline & $\mu \mathrm{CT}$ & histology & $\mu \mathrm{CT}$ & histology & & \\
\hline SJ892 & Yes & Yes & 2 & 1 & $1-2$ & 1 to 3 \\
\hline STE311 & Yes & Yes & 1 & 1 & 1 & $1+$ \\
\hline STE15 & No & Yes & 0 & 1 & 0.5 & DIGD \\
\hline
\end{tabular}

[Figure 3, here, 2 columns]

STE311 presents no skeletal signs of rickets or morphological changes of the pulp chamber on X-ray assessment, but shows one layer of IGD under the crown. This deficiency event is identified in both $\mu \mathrm{CT}$ (Figure 4a-c) and histological images (Figure 4d) and occurred at the age of 1 year (Table 2). The age of the vitamin D deficiency is consistent with the absence of changes in pulp chamber morphology since pulp chamber formation has not yet been initiated at this young age. $\mu \mathrm{CT}$ images show the same severity of deficiency as the histological thin section, with a grade $1+$ of IGD. This case illustrates how $\mu \mathrm{CT}$ analysis can reveal a deficiency event which has not been highlighted by either bone macroscopic or radiographic analyses.

[Figure4, here, 2 columns]

\section{Discussion}

For the first time, micro-computed tomography has been used to detect tooth defects linked to vitamin D deficiency in archaeological skeletons. Evaluation of teeth from the three individuals considered here illustrates how $\mu \mathrm{CT}$ can be useful for IGD detection and the study of vitamin D deficiency in past populations.

As we have seen for these archaeological samples, in addition to its many other uses, $\mu \mathrm{CT}$ images also permit analysis of the internal structures of human remains and, in our cases, pathological tooth microstructure, in a detail similar to what is required in histological analysis, as previously demonstrated for bone microarchitecture (Fajardo et al., 2002). Indeed, IGD, when it is linked to deficiency, is due to unfused minerals of dentine that produce a void within the mineral matrix. Thus, IGD has the potential to be identified by $\mu \mathrm{CT}$ analysis due to differences in the density of material that, in turn, leads to differences in X-ray absorption. Consequently, IGD, as a void, should appear as a small black area on $\mu \mathrm{CT}$ images due to its effects on grey values (Ribeiro et al., 2015). 
STE15, in which potential radiological features of deficiency and small amounts of developmental IGD were present, illustrates both the advantages and limits of $\mu \mathrm{CT}$. We identify three possible reasons why this small amount of IGD is not detectable with $\mu \mathrm{CT}$ : (1) developmental IGD (DIGD) does not have the same characteristics and is not detected with $\mu \mathrm{CT}$. Developmental IGD is an imperfectly calcified dentine situated near the dentinal periphery that does not follow the incremental lines. DIGD can be mistaken for low grade IGD, but its location, size, and amount indicate that these abnormalities are natural anomalies that occurred during the development of the tooth (D'Ortenzio et al., 2018). It seems likely that $\mu C T$ assessment may avoid the problem of having to differentiate developmental IGD because the defects produced in dentine are too small to be visible on $\mu \mathrm{CT}$ at the resolution level used here. (2) It is possible that IGD produced by deficiency could not be identified with $\mu C T$ because of reparative dentine formation due to occlusal wear, but a severe deficiency should leave mineralisation defects. (3) Finally, a technical reason is also possible to explain the differences in what is seen using histology and $\mu \mathrm{CT}$. A histological thin section is $100 \mu \mathrm{m}$ thick, whereas a $\mu \mathrm{CT}$ slice is $11 \mu \mathrm{m}$ thick. Thus, the histological section is almost 10 times thicker than the $\mu \mathrm{CT}$ slices and comparatively contains the information of almost $10 \mu \mathrm{CT}$ slices superimposed. Thereby, the non-detection of really slight IGD degree with $\mu \mathrm{CT}$ could be resolved by using a better $\mu \mathrm{CT}$ resolution (lower than $11 \mu \mathrm{m}$ ), but it is likely that for most investigations not seeing this detail would be an advantage.

The $\mu \mathrm{CT}$ analyses share with histological analysis the advantages of detecting vitamin D deficiency events with different severities that are not observable in bones or on X-ray analysis. They permit the identification of the number of deficiency events experienced by individuals during the developmental period. Moreover, the individual age when these events occurred can be estimated. These signs are useful in the osteological assessment of individual health status. The fact that, to date, IGD lower than grade 1 seems to be poorly or not detected at all with $\mu \mathrm{CT}$ may be used as an advantage as it appears likely that developmental IGD is unlikely to be picked up with $\mu \mathrm{CT}$. However, failure to pick up lower grades could result in misinterpretation of the pattern of vitamin D deficiency. For example, SJ892 $\mu$ CT showed two episodes of deficiency whereas histological analysis revealed there was a longer period of deficiency that was less sever (grade 1).

$\mu \mathrm{CT}$, in addition to being non-destructive, permits the detection of IGD in all three dimensions. Thus, by exploring all of the dentine, $\mu \mathrm{CT}$ offers researchers the absolute certainty that no IGD event has been missed, and the capacity to add to understandings of the occurrence and timing of pathological changes. $\mu \mathrm{CT}$ also permits analysis of tooth microstructures that lead to better understanding of the timing of deficiency, when a deficient episode begins and when the period of deficiency ends. As it is now been demonstrated that $\mu \mathrm{CT}$ highlights IGD layers, it will be also possible to model them in $3 \mathrm{D}$, avoiding the approximation or estimation required of a $2 \mathrm{D}$ image, as well as to precisely quantify them to improve the IGD severity scoring method.

\section{Conclusion}

Vitamin D deficiency is experienced by numerous populations through time and across geographic space, and especially in individuals not adapted to their environment or with cultural 
practices limiting vitamin D production in the skin (Brickley et al., 2017). Thus, detection of vitamin D deficiency through analysis of IGD in past populations can aid the understanding of social practices, dietary habits, and environmental conditions. Up to the present time cutting teeth was a major obstacle to the study of rare human and non-human skeletal remains. With $\mu \mathrm{CT}$ analysis, restrictions regarding destructive analysis are no longer an obstacle. $\mu \mathrm{CT}$ analysis to detect IGD and to discuss vitamin D deficiency represents a compelling alternative to the use of histological methods.

\section{Acknowledgements}

We thank our grant sponsors, the Regional Council of Aquitaine (France), Labex des Sciences Archéologiques de Bordeaux ( $\operatorname{LaScArBx}$ ), and the Excellence Initiative (IdEx) of the University of Bordeaux (France, call 2016-1, number 20161123) awarded to Megan Brickley. This research was undertaken, in part, thanks to funding from the Canada Research Chairs program. We are also grateful to Maryelle Bessou (PACEA) for the production of radiographs and Patrice Courtaud (PACEA) for permitting access to and welcoming us to the Ostéothèque de Pessac. We also thank the anonymous reviewers for their useful comments that helped to improve this article.

\section{References}

Benazzi, S., Fornai, C., Bayle, P., Coquerelle, M., Kullmer, O., Mallegni, F., Weber, G.W., 2011. Comparison of dental measurement systems for taxonomic assignment of Neanderthal and modern human lower second deciduous molars, J. Hum. Evol. 61, 320-326.

Brickley, M., Mays, S., Ives, R., 2010. Evaluation and interpretation of residual rickets deformities in adults, Int. J. Osteoarcheol. 20, 54-66.

Brickley, M.B., D’Ortenzio, L., Kahlon, B., Schattmann, A., Ribot, I., Raguin, E., Bertrand, B., 2017. Ancient Vitamin D Deficiency: Long-Term Trends, Current Anthropol. 58, 420-427.

Brickley, M.B., Mays, S., George, M., Prowse, T.L., In press. Analysis of patterning in the occurrence of skeletal lesions used as indicators of vitamin D deficiency in subadult and adult skeletal remains, Int. J. Paleopathol.

Brickley, M.B., Moffat, T., Watamaniuk, L., 2014. Biocultural perspectives of vitamin D deficiency in the past, J. Anthropol. Archaeol. 36, 48-59.

Cardoso, H.F.V., 2006. Brief communication: The collection of identified human skeletons housed at the Bocage Museum (National Museum of Natural History), Lisbon, Portugal, Am. J. Phys. Anthropol. 129, 173-176.

Coqueugniot, H., Colombo, A., Rittemard, C., Baker, O., Dutailly, B., Dutour, O., Lenoir, N., 2015. Micro-CT characterization of archeological bones, in: Long, B. (Ed.), 2nd International Conference on Tomography of Materials and Structures, INRS-ETE, Québec, Canada, pp. 643647.

D'Ortenzio, L., Ribot, I., Kahlon, B., Bertrand, B., Bocaege, E., Raguin, E., Schattmann, A., Brickley, M., In press. The rachitic tooth: The use of radiographs as a screening technique, Int. J. Paleopathol.

D'Ortenzio, L., Ribot, I., Raguin, E., Schattmann, A., Bertrand, B., Kahlon, B., Brickley, M., 2016. The rachitic tooth: A histological examination, J. Archaeol. Sci.74, 152-163. 
D’Ortenzio, L., Kahlon, B., Peacock, T., Salahuddin, H., Brickley, M., 2018. The rachitic tooth: Refining the use of interglobular dentine in diagnosing vitamin D deficiency, Int. J. Paleopathol. 22, 101-108.

De Filippo R., Peixoto X., C., S., 1986. Toulouse. Fouilles archéologiques de la place SaintEtienne, Rapport de fouilles archéologiques.

De Filippo R., Peixoto X., C., S., 1988. Toulouse place Saint-Etienne. Rapport de fouille 1987., Rapport de fouilles archéologiques.

Fajardo, R.J., Ryan, T.M., Kappelman, J., 2002. Assessing the accuracy of high-resolution Xray computed tomography of primate trabecular bone by comparisons with histological sections, Am. J. Phys. Anthropol. 118, 1-10.

Foster, B.L., Nociti Jr, F.H., Somerman, M.J., 2014. The rachitic tooth, Endocr. Rev. 35, 1-34.

Hillson, S., 1996. Sequence of timing of dental growth, in: Hillson, S. (Ed.), Dental Anthropology, Cambridge University Press, Cambridge, pp. 118-147.

Huh, S.Y., Gordon, C.M., 2008. Vitamin D deficiency in children and adolescents: Epidemiology, impact and treatment, Rev. Endocr. Metab. Disord. 9, 161-170.

Hunt, D.R., Albanese, J., 2005. History and demographic composition of the Robert J. Terry anatomical collection, Am. J. Phys. Anthropol. 127, 406-417.

Immel, A., Le Cabec, A., Bonazzi, M., Herbig, A., Temming, H., Schuenemann, V.J., Bos, K.I., Langbein, F., Harvati, K., Bridault, A., Pion, G., Julien, M.A., Krotova, O., Conard, N.J., Münzel, S.C., Drucker, D.G., Viola, B., Hublin, J.J., Tafforeau, P., Krause, J., 2016. Effect of X-ray irradiation on ancient DNA in sub-fossil bones - Guidelines for safe X-ray imaging, Sci. Rep. 6.

Jablonski, N.G., Chaplin, G., In press. The roles of vitamin D and cutaneous vitamin D production in human evolution and health, International Journal of Paleopathology.

Jones, G., In press. The discovery and synthesis of the nutritional factor vitamin D, Int. J. Paleopathol.

Mays, S., Brickley, M., Ives, R., 2006. Skeletal manifestation of rickets in infants and young children in a historic population from England, Am. J. Phys. Anthropol. 129, 362-374.

Moorrees, C.F.A., Fanning, E.A., Hunt, E.E., 1963. Age variation of formation stages for ten permanent teeth, J. Dent. Res. 42, 1490-1502.

Ribeiro, T.R., Costa, F.W.G., Soares, E.C.S., Williams, J.R., Jr., Fonteles, C.S.R., 2015. Enamel and dentin mineralization in familial hypophosphatemic rickets: A micro-CT study, Dentomaxillofac. Rad. 44, 20140347.

Tafforeau, P., Smith, T.M., 2008. Nondestructive imaging of hominoid dental microstructure using phase contrast X-ray synchrotron microtomography, J. Hum. Evol. 54, 272-278.

Wang, S., 2009. Epidemiology of vitamin D in health and disease, Nut. Res. Rev. 22, 188-203. Ziegler, T.E., Kapoor, A., Hedman, C.J., Binkley, N., Kemnitz, J.W., 2015. Measurement of 25-hydroxyvitamin $\mathrm{D}_{2 \& 3}$ and 1,25-dihydroxyvitamin $\mathrm{D}_{2 \& 3}$ by tandem mass spectrometry: A primate multispecies comparison, Am. J. Primatol. 77, 801-810. 
Figure 1: Bone and dental features associated with the presence or absence of vitamin D deficiency in the three individuals analysed. (a) Abnormal bowing of the left and right tibiae and fibulae of individual SJ892 highlighting the appearance of residual rickets, (b) pulp chamber morphological changes potentially linked to rickets in individuals SJ892 and STE15 (white arrows) in comparison with STE311 showing normal pulp chamber shape.

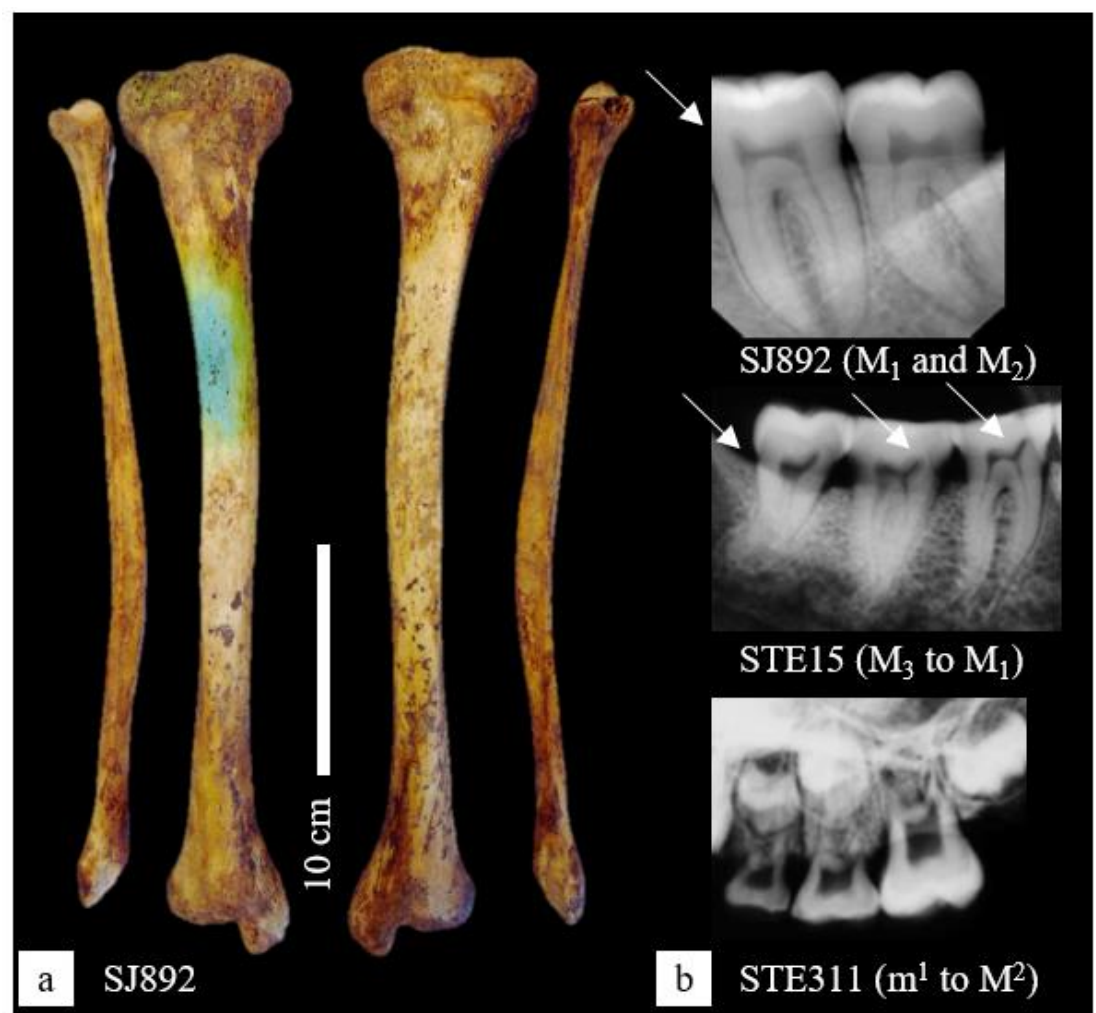


Figure 2: Comparison between $\mu \mathrm{CT}$ appearance for the SJ892 lower right first incisor and histological appearance for the SJ892 lower right canine. (a) Detail of the $\mu \mathrm{CT}$ coronal slice, (b) Detail of the $\mu \mathrm{CT}$ sagittal slice, white arrows show the two layers of IGD. (c) Histological image, orange circles indicate the IGD areas.

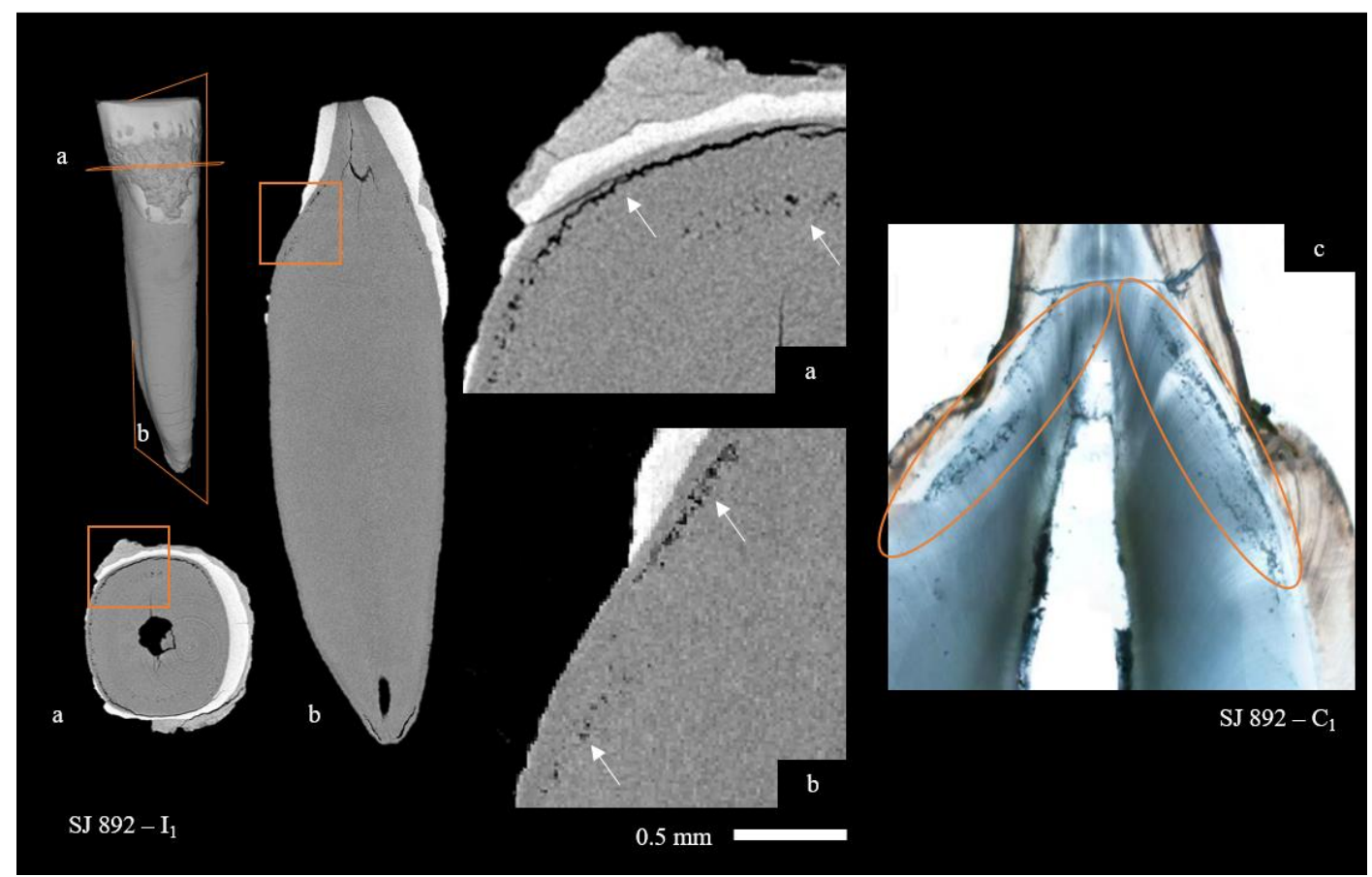


Figure 3: Comparison between $\mu \mathrm{CT}$ and histological for the STE 15 lower first left molar. (a) Coronal view, (b) sagittal view and in detail in the orange square, (c) longitudinal view. (d) Histological image, white arrows indicate IGD.

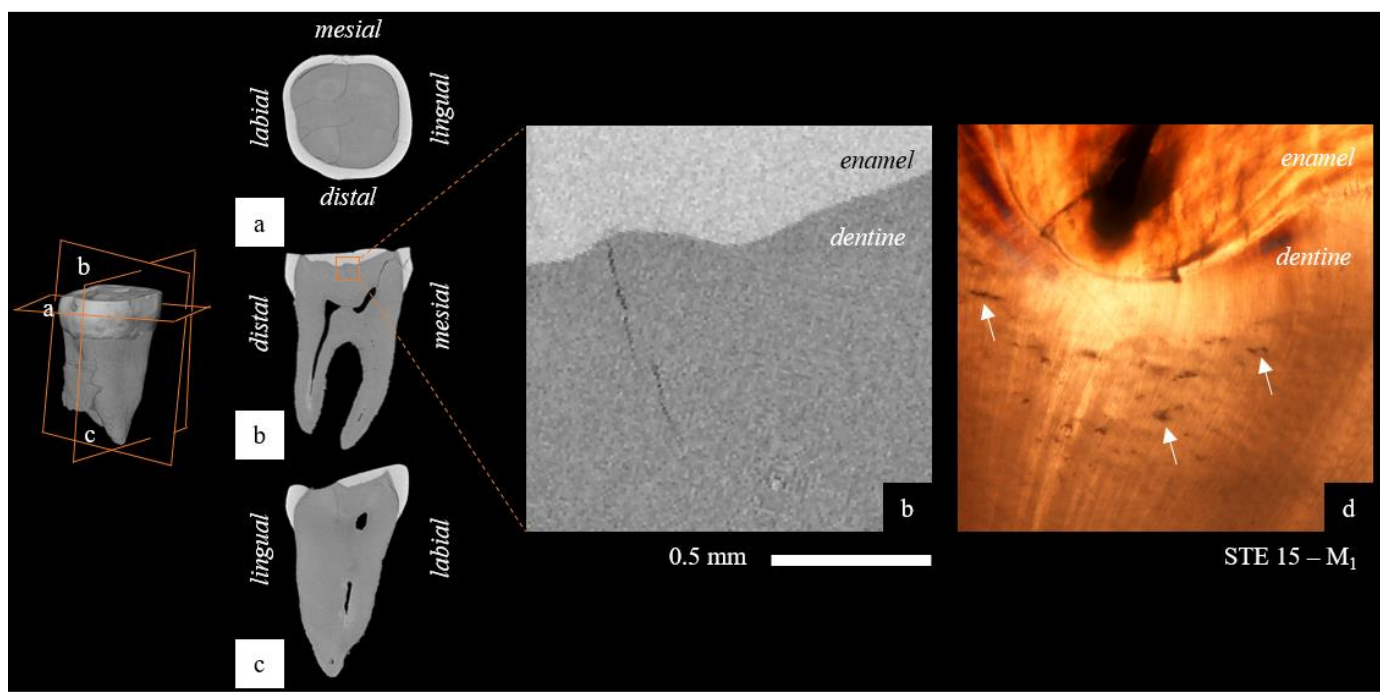


Figure 4: Comparison between $\mu \mathrm{CT}$ and histological appearance of the STE 311 upper first left molar. (a) Coronal view and in detail (orange square) of the tooth with IGD, (b) sagittal view and in detail (orange square) of the tooth with IGD, (c) longitudinal view and in detail (orange square) of the tooth with IGD white arrows indicate IGD. (d) Histological image, white arrows indicate IGD.

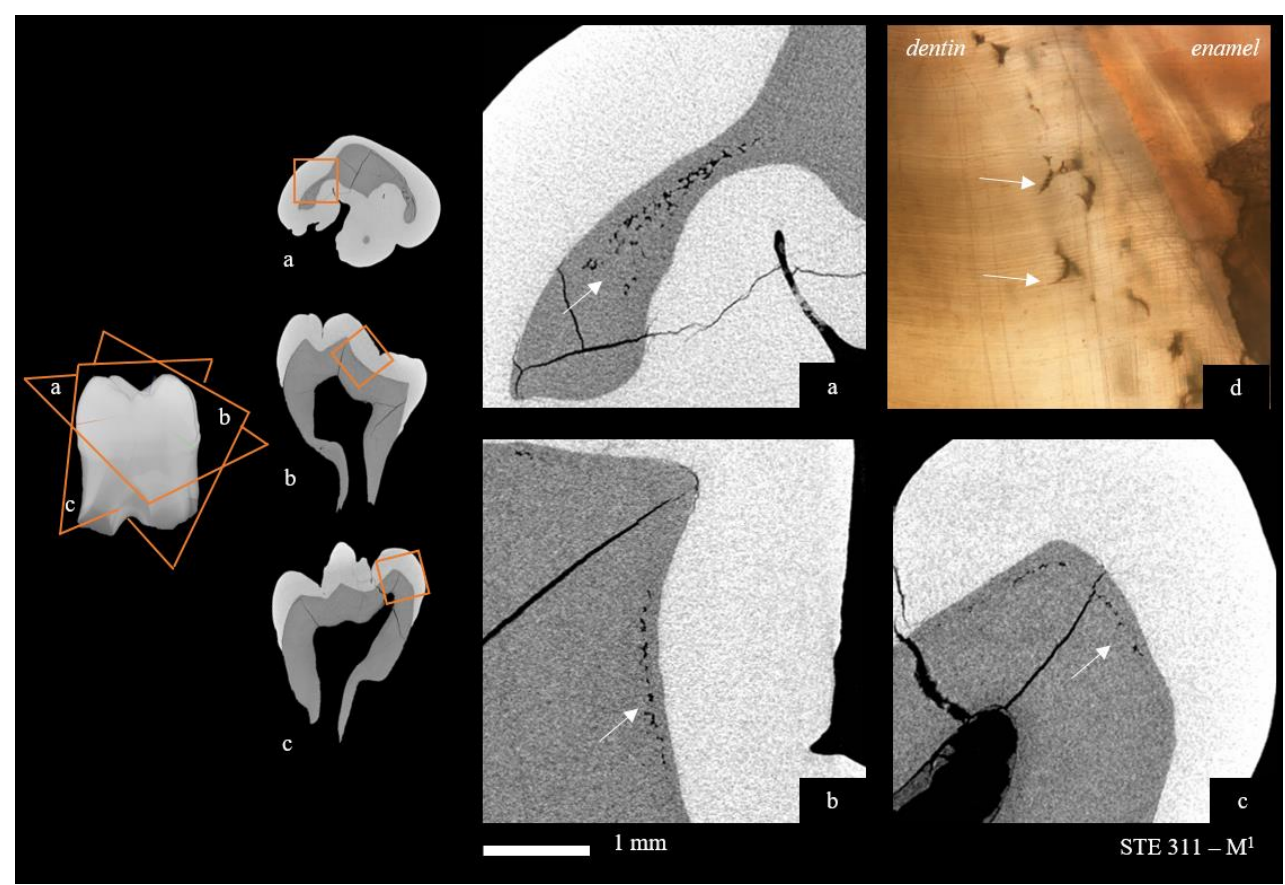

